\title{
FAMÍLIA E ESPORTE: A INFLUÊNCIA PARENTAL SOBRE A PARTICIPACÃO DOS FILHOS NO FUTSAL COMPETITIVO
}

DOI: 105902/0102830813819

Data de Submissão: 13/05/2014

Data de Aprovação: 01/07/2015

\section{Gerard Maurício Martins Fonseca}

gmmfonse@ucs.br Universidade de Caxias do Sul

\section{Erika Spritze Stela}

erika_spritze@hotmail.com Universidade de Caxias do Sul

RESUMO: O objetivo deste estudo foi identificar os fatores parentais determinantes para a participação dos filhos no futsal competitivo. Participaram 149 adultos, sendo 84 homens e 65 mulheres com filhos nas categorias sub-9, sub-11 e sub-13 de três clubes de futsal de Caxias do Sul-RS. O instrumento utilizado para a coleta de dados foi o Questionário Para os Pais (QPP). Os resultados mostraram que o esporte é valorizado e praticado pelos pais. $O$ estudo conclui que o incentivo dos pais constrói um ambiente saudável para que a criança desenvolva suas potencialidades, segurança e motivação para praticar o futsal e que não há diferença significativa no comportamento entre pais e mães.

Palavras-chave: Esporte. Futsal. Motivação. Família. 


\section{Introdução}

O futebol de salão, denominado futsal atualmente, teve seu surgimento na Associação de Moços de Montevidéu, no Uruguai, nos anos trinta, criado pelo professor Juan Carlos Ceriani. Desde então, o futsal sofreu algumas mudanças e evoluções com o decorrer dos anos. Para Fonseca (2000), o futsal se tornou um esporte atraente e competitivo e exige um maior rendimento nos aspectos cognitivos, psicológicos e motores de seu praticante. Atualmente, o futsal é amplamente conhecido e difundido entre a população e preenche a lacuna deixada pelo futebol, por haver cada vez menos campos disponíveis para a prática nos grandes centros.

Conforme Arins e Silva (2007) o futsal é um jogo de inúmeras ações motoras com e sem a posse de bola, em que seus praticantes alteram frequentemente o ritmo de corrida, a direção e/ou sentido e a distância de corrida em cada ação efetuada $\mathrm{O}$ treinamento exige do participante grande demanda física, pois as ações são realizadas em grande velocidade, força e potência.

Segundo Fonseca e Silva (2002), no futsal os aspectos técnicos, táticos e físicos, que compõem sua estrutura fundamental, surgem de forma integrada. Neste sentido, existe a necessidade de um desenvolvimento mais completo do jogador de futsal, não bastando apenas dominar a técnica, mas também, dar resolução aos problemas táticos surgidos durante o jogo. O futsal se manifesta de forma estratégica, obrigando as equipes a um constante confronto, atuando juntos, atacando e defendendo ao mesmo tempo.

Antes de chegar a um nível de proficiências adequado, o jogo passa por etapas de desenvolvimento e aprimoramento, que invariavelmente inicia na infância. O processo de ensino do futsal compreende uma série de variáveis e fatores complexos, que vão desde o aprendizado das questões do jogo, como a técnica e a tática, ao convívio social em grupo e o ensino de valores morais, onde o profissional que ensina o jogo deve orientar para uma boa iniciação esportiva. 
A iniciação esportiva é o período em que a criança começa a aprender de forma mais específica e planejada a prática esportiva. Santana (1998) entende a iniciação esportiva como o período em que a criança inicia a prática regular e orientada de um treinamento planejado, aprendendo uma modalidade esportiva. O objetivo é dar continuidade ao seu desenvolvimento de forma integral, aumentando gradualmente o rendimento, além da participação periódica em competições esportivas. Para Ramos e Neves (2008), a especilização esportiva precoce caracteriza-se por cargas de treinos mais intensos, que promovem o desenvolvimento rápido em fases iniciais e que podem levar a um esgotamento prematuro de rendimento na modalidade praticada.

Diversas variáveis influenciam o processo de desenvolvimento da criança no contexto do esporte, as interferências advindas das inter-relações sociais constituem aspectos fundamentais para o estabelecimento de um ambiente com condições favoráveis para o processo de formação pessoal e esportivo. O ser humano possui inúmeras situações do seu cotidiano que o faz motivar-se, tanto de forma interna, quanto externa. Por isso, inferimos a presença da motivação observando o comportamento de um ser humano, ou seja, é o quanto esse indivíduo encontra-se envolvido com o alcance de sua meta ou objetivo. No caso do futsal, como nos demais esportes, a motivação é um fator determinante para o ingresso no processo de aprendizagem, bem como para sua continuidade.

Para Magill (1984), a motivação está associada à palavra motivo, que pode ser definido como alguma força interior, impulso, intenção que leva a pessoa a fazer algo ou agir de certa forma, e que afeta a compreensão da aprendizagem de habilidades, motoras devido a seu papel na iniciação, manutenção e intensidade do comportamento.

A motivação é ponto de referência quando um indivíduo deseja realizar algo. Conforme Marques (2003) trata-se, pois, de uma série de condições que satisfaçam o desejo de começar ou continuar a fazer alguma coisa, ou seja, nossos desejos mais internos e desconhecidos são impulsionadores de atividades que nos levam 
a assumir determinado comportamento. No esporte, é o combustível para o atleta. Segundo Samulski (2002), a motivação para a prática esportiva depende da interação entre a personalidade (expectativas, motivos, necessidades e interesses) e fatores do meio ambiente, como facilidades, tarefas atraentes, desafios e influências sociais.

Para Verardi e De Marco (2008) os aspectos motivacionais são os principais fatores para a realização de toda e qualquer atividade seja ela no plano motor ou cognitivo, permitindo a máxima eficiência da aprendizagem. Podemos considerar que a chave da motivação está na satisfação que o indivíduo obtém do seu comportamento. O esporte é um fenômeno que chama a atenção dos indivíduos na sociedade contemporânea. Esse modelo social inclui, entre outras instituições, a família, a escola e o clube esportivo, os quais afetam os indivíduos em relação às suas potencialidades e à sua formação esportiva.

Na infância, o incentivo dos familiares é fundamental para a prática esportiva bem sucedida e em si, é demasiado complexo; depende de diversos fatores diretamente relacionados. A persistência, a autoestima, confiança e motivação também estão presentes no cotidiano da iniciação esportiva. Desta forma, a família apresenta um ambiente social primário, onde o jovem pode desenvolver sua potencialidade para a prática esportiva.

A qualidade dos incentivos e os exemplos dos adultos (pais) variam em termos de engajamento como a principal força de influência aos filhos. O incentivo, portanto, é uma atividade adulta essencial para as crianças adquirirem autoestima, controle e consciência de ter o pai ou a mãe como um agente incentivador. É uma indicação de que o mundo dos adultos exerce uma atividade efetiva sobre a vida esportiva das crianças.

Conforme Simões, Böhme e Lucato (1999), não há dúvidas de que um dos papéis essenciais do pai e da mãe seja o de incentivar as crianças no sentido de participarem do esporte e, assim, dar a elas a mais estreita cooperação, acelerando sua prontidão esportiva, sua maturidade e uma grande variedade de atividades 
no mundo dos campos, piscinas, pistas e quadras esportivas. De acordo com Fonseca (2000), a realidade do futsal competitivo entre os jovens praticantes na região nordeste do Rio Grande do Sul não é diferente da realidade do país. Esta região é um polo muito forte, pois o clima é ameno, o que possibilita o aumento da prática de esportes em ginásios, dando ao futsal uma popularidade muito grande, principalmente em Caxias do Sul, que possui diversos clubes de futsal com suas escolinhas.

Assim, a participação dos pais no desenvolvimento esportivo, especialmente no futsal, é um tema de importância para o esporte caxiense e regional. Questões relacionadas aos interesses de pais e filhos na prática esportiva devem ser discutidas e, no presente caso, pesquisadas.

Desta forma, o presente estudo tem como objetivos, identificar os fatores parentais determinantes para a eleição do futsal como iniciação esportiva dos filhos.

\section{Metodologia}

O presente estudo é caracterizado como uma pesquisa quantitativa, transversal e descritiva, conforme Thomas, Nelson e Silverman (2007). Participaram do estudo 149 adultos, sendo 84 pais e 65 mães que possuíam filhos nas categorias de base sub-9, sub-11 e sub-13 de três clubes de futsal que participaram do Campeonato Regional do Estado do Rio Grande do Sul, chamado Copa Nordestão, no ano de 2013. Esta competição é tradicional na história da região e cidade de Caxias do Sul na qual as escolinhas e clubes tradicionais de futsal participam todos os anos. Os critérios de inclusão da amostragem definiu que os clubes estudados estavam competindo na Copa Nordestão e tinham mais de cinco anos de participação na mesma. Além disso, as crianças tinham mais de dois anos de participação em competições e estavam nas categorias sub-9, sub-11 e sub-13.

O instrumento utilizado para coleta de dados foi o Questionário Para os Pais (QPP) validado por Verardi (2004). O questionário identificou os motivos que 
determinaram as influências dos pais sobre a iniciação esportiva de seus filhos na modalidade de futsal. O QPP consta de 21 questões, sendo 3 sócio-culturais, 3 sócio-econômicas, e 15 questões sobre a importância atribuída à prática esportiva e aos jogos de competição e incentivo da família para prática de atividades esportivas.

Primeiramente, foram realizados contatos prévios com os coordenadores das categorias de base dos clubes de futsal participantes da pesquisa. Em seguida, foi feito um contato com os técnicos das equipes para explicar-lhes os objetivos do trabalho. Após o contato com clube e os técnicos, os pais foram contatados e, da mesma forma, convidados a participar. Após esta etapa, os participantes assinaram o Termo de Consentimento Livre e Esclarecido (TCLE), autorizando sua participação na pesquisa.

Os dados foram coletados antes do início da competição, procurando, assim, evitar a interferência dos resultados obtidos pela equipe e também do desempenho dos atletas nos jogos. Este procedimento objetivava minimizar o surgimento de variáveis intervenientes como a motivação, o estresse, e outras relacionadas à prática competitiva por crianças e seus respectivos resultados.

O questionário foi entregue com um envelope de lacre para os pais, que tiveram quinze dias para devolver aos clubes. O TCLE foi entregue na mesma data que o questionário, porém a parte, mantendo o sigilo do estudo. Após esse período, foi recolhido o instrumento para análise. O questionário foi entregue em todos os clubes na mesma data. Cabe salientar que, antes da entrega dos questionários para os pais eles receberam os devidos esclarecimentos quanto ao objetivo da pesquisa e preenchimento do instrumento.

Os resultados foram analisados estatisticamente seguindo as orientações de Motta (2006), a partir da construção de tabelas de frequência para a estatística descritiva não inferencial. Para comparar a diferença entre a opinião dos pais e das mães, utilizou-se o teste Qui Quadrado com nível de significância de $p<0,05$. 


\section{Análise dos resultados}

A cidade de Caxias do Sul na Serra Gaúcha por ter um clima bastante ameno, possui inúmeros ginásios e clubes esportivos e por isso tem uma grande tradição na modalidade esportiva do futsal (FONSECA, 2000). Desde muito cedo, crianças aprendem a jogar esse esporte e muitas vezes essa prática acaba perdurando ao longo dos anos, seja praticada de forma recreativa o que também pode-se chamar de amadora, ou mesmo profissional. Nessa pesquisa realizada em três clubes que atenderam aos critérios de inclusão, 56,4\% dos pais participantes eram do sexo masculino, e $43,6 \%$ eram do sexo feminino. Sendo que a maioria dos pais apresenta uma faixa etária entre os 31 e 40 anos como pode-se observar na tabela 1.

Tabela 1: Distribuição da idade dos avaliados

\begin{tabular}{r|l} 
Faixa Etária & $\%$ \\
\hline 25 anos ou menos & $6,7 \%$ \\
26 anos a 30 anos & $10,1 \%$ \\
31 anos a 40 anos & $56,4 \%$ \\
41 anos a 50 anos & $24,8 \%$ \\
Acima de 50 anos & $2,0 \%$
\end{tabular}

Os pais pesquisados atuam na sua maioria no ramo profissional dos Serviços $46,3 \%$, enquanto $27,5 \%$ atuam na Indústria e por último $20,8 \%$ no ramo do Comércio. Sendo a sua maior escolaridade o Ensino Médio com 47\%, após o Ensino Superior com 34,9\% e o Ensino Fundamental com 17,4\%. Ainda que seja uma cidade de característica industrial, o setor dos serviços vem apresentando um crescimento exponencial na cidade, como no resto no país. Segundo o IBGE, o setor de serviços teve um crescimento nominal de 6,6\% em agosto de 2013 em relação ao mês de julho de 2012, sendo que o estado do Rio Grande do Sul aparece como segunda maior taxa de crescimento. Esse crescimento se deu 
ao baixo investimento necessário para se abrir um negócio e o crescimento da demanda por terceirizados têm colaborado para que o setor de serviços venha registrando índices de crescimento acima do verificado em setores como indústria e comércio.

Os resultados da pesquisa mostram que a atividade que os pais mais se dedicam em seus momentos de tempo livre é a prática de atividades esportivas. Esta situação apareceu como a primeira opção dos entrevistados sendo 52,4\%. Já como a segunda opção os pais destacaram a leitura com 50\% e como terceira opção ficou a televisão, com 29\%. Com a globalização e a facilidade dos meios de comunicação, esses fatores auxiliam os indivíduos na busca de informações, pois as pessoas estão mais expostas a estímulos visuais, o que amplia o universo individual e familiar, pondo o indivíduo em contato com outras culturas e também o possibilita a vivência de atividades que proporcionam prazer e satisfação, como por exemplo, acompanhar os eventos esportivos. Desta forma, os resultados justificam a importância e presença do esporte na vida social das famílias pesquisadas. $O$ esporte faz parte da cultura das famílias. Pode-se confirmar esse dado observando os resultados encontrados quanto a participação dos pais em competições esportivas na tabela 2.

Tabela 2: Participação parental em competições

\begin{tabular}{l|c} 
Participação em competições & $\%$ \\
\hline \multicolumn{1}{c|}{ Não } & 25,5 \\
Sim, nível recreativo & 26,2 \\
Sim, nível amador & 40,2 \\
Sim, nível profissional & 11,1
\end{tabular}


Com o envolvimento direto dos pais com a prática esportiva, é mais fácil que haja um incentivo maior para que os seus filhos também sigam por esse caminho, seja por um esporte em específico ou por vários esportes. A relação entre pais e filhos se torna forte a partir dos exemplos positivos demonstrados pelos adultos. A criança percebendo o prazer e satisfação em que seus pais praticam atividades esportivas acaba apresentando a mesma vontade de praticar. O exemplo familiar faz com o filho queira praticar esportes também.

A atividade esportiva é muito importante no desenvolvimento da criança e do adolescente, fazendo com que a criança crie responsabilidade, dedicação e força de vontade. O esporte é um agente importante no processo de socialização de crianças e adolescentes, influenciados por familiares, professores, técnicos e amigos. Ele tem um papel fundamental para o desenvolvimento das capacidades físicas e motoras nas idades iniciais (GALLAHUE; OZMUN; 2003), e por isso o incentivo é de suma importância. A presente pesquisa verificou (tabela 3) que $69,8 \%$ dos pais incentivam e proporcionam que os filhos pratiquem alguma outra modalidade esportiva além do futsal. Este dado reforça mais uma vez a cultura esportiva vigente dentre os avaliados, pois somente $30,2 \%$ não incentivam e ao mesmo tempo não proporcionam o acesso a estas práticas.

Tabela 3: Incentivo para prática de esportes.

\begin{tabular}{c|c} 
Incentivo para outras modalidades & $\%$ \\
\hline Sim & $69,3 \%$ \\
Não & $30,2 \%$
\end{tabular}

Quanto às opções esportivas praticadas além do futsal, o futebol aparece como a primeira opção de modalidade, apresentando 48,3\% de preferência. Como segundas e terceiras opções apareceram dois esportes individuais, a Natação com 9,4\% e Lutas 7,4\%. Para Giacomoni (2013) a grande valorização do futebol 
em nosso país acabou tornando e transformando os atletas profissionais num negócio lucrativo, que movimenta grandes quantias anuais. A obsessão destes jovens atletas em se tornar jogadores de futebol, acontece a partir da idolatria de jogadores reconhecidos pelo seu talento e habilidade, mas também pela fama e glamour que esse esporte apresenta mundialmente.

Em relação ao futebol, dados da FIFA apontam que no Brasil o futebol é uma modalidade com grande capacidade de envolvimento da população, gerando diversos empregos, onde: trezentos mil empregos diretos, trinta milhões de praticantes (formais e não formais), quinhentos e oitenta mil participantes em treze mil times que participam de jogos organizados, quinhentos e oitenta estádios com capacidade para abrigar mais de cinco milhões de torcedores, cerca de quinhentos clubes profissionais disputando uma média de noventa partidas por ano. (LEONCINI e SILVA, 2005).

A pesquisa reforçou esse dado verificando que $85,9 \%$ dos pais entrevistados gostariam que seus filhos se tornassem jogadores profissionais, e apenas 14,1\% não gostariam, não havendo diferença estatisticamente significativa entre as aspirações de pais e de mães. À medida que o nível de exigência dos pais aumenta, é de se esperar que essas influências sejam ainda mais importantes para a compreensão da prática esportiva familiar. Os pais pesquisados tem uma relação direta com a prática esportiva e como o esporte é visto como um modelo de ascensão social rápido, pode ser possível que haja uma ligação com forte nível de exigência dos familiares na fase de desenvolvimento das personalidades infantis. Conforme Simões, Böhme e Lucato (1999), a forma e o grau de exigência adotado pelos pais para que os filhos se tornem bons atletas demonstra claramente que estão preocupados com a consecução de seus fins, portanto, submetendo voluntariamente os filhos às suas exigências pessoais e necessárias para que eles se tornem bons atletas.

A exigência excessiva é um fator determinante que possui uma grande influência na prática esportiva das crianças. As pressões existentes para se tornarem bons 
atletas e a necessidade da vitória, podem de uma maneira negativa, causar na criança a ansiedade, frustração entre outros sentimentos, levando muitas vezes ao abandono do esporte. Na cidade de Caxias do Sul, existe um alto nível de abandono esportivo no futsal (FONSECA, MANGINI; ZECHIN, 2013), decorrentes deste tipo de comportamento.

Os praticantes que atingem níveis de excelência referem como elemento fundamental um grande suporte dos familiares mais próximos. O ambiente motivacional que se constrói à sua volta, bem como os estímulos para ultrapassar os desafios e dificuldades inerentes ao processo, aliados a valorização que sentem por parte dos pais nessa atividade, se constituem fatores decisivos que mantêm a energia motivacional e por isso evita o abandono. (SERPA, 2003).

Segundo Figueiredo (2000), a ansiedade é vista como uma das principais variáveis que interferem no desempenho das crianças. Os pais quando perguntados sobre o nível de ansiedade do seu filho antes do jogo, em uma escala entre 0 e 10, apontaram níveis altos. 18,8\% detectaram nível 8 de ansiedade, 18,1\% nível 7 e $14,1 \%$ nível 5 . Na opinião dos pais a maioria das crianças sofre pressão, medo e ansiedade antes de entrar em um jogo, causada, por exemplo, pela obrigação de vencer, algo que é característico em uma sociedade na qual exalta a emoção da vitória e o sofrimento da derrota.

Os resultados encontrados sobre a percepção dos pais sobre o principal comportamento do seu filho durante o jogo mostram que, na percepção dos pais, seus filhos permanecem com o fator da ansiedade também ao longo da partida, podemos analisar isso na tabela 4:

Tabela 4: Percepção parental do comportamento do filho

\begin{tabular}{l|l} 
Comportamento & $\%$ \\
\hline Ansioso & $55,7 \%$ \\
Calmo & $33,5 \%$ \\
Outros & $10,8 \%$
\end{tabular}


O fator da ansiedade por conta das crianças pode ser explicado pelo comportamento dos pais na arquibancada durante os jogos. A pesquisa verificou que $73,2 \%$ "torcem gritando, gesticulando e incentivando", 15,7\% "assistem tranquilamente" e 6,7\% "ficam apreensivos". Na infância, o incentivo dos familiares é fundamental para o êxito da prática esportiva. A qualidade dos incentivos dados durante os jogos e também os exemplos dos adultos tem uma grande força de influência aos filhos. O incentivo, portanto, é uma atividade adulta essencial para as crianças adquirirem autoestima, controle e consciência de ter o pai como um agente incentivador, ao contrário disso, a criança pode se sentir insegura de realizar qualquer atividade e por isso adquirir ansiedade, pois se sente cobrada e tem medo de errar. Quanto à ansiedade dos pais durante os jogos, a pesquisa não encontrou diferenças significativas entre pais e mães.

A Liga Caxiense de Futsal possui regras para os jogos de categorias de base. Um jogo é dividido em dois tempos de 15 minutos, onde no primeiro tempo, é sub-dividido também em dois tempos. No primeiro 7'30 a equipe joga com seu time titular, tendo que no outro 7'30, substituir todos os seus jogadores pelos reservas. Esse é um fator externo que a equipe acaba por se submeter para que todos tenham a oportunidade de jogar. De maneira geral, 59,7\% dos pais não se importam em ver seu filho sendo substituído, e 40,3\% não gostam. Quando analisamos esse dado pelo valor absoluto, 44 pais de um total de 84 , não gostam da substituição. Em contra partida, de 65 mães, apenas 16 delas não gostam de ver seu filho ser substituído. Esse é um dado importante, que nos mostra a maior insatisfação e exigência paterna.

Um trabalho conduzido por Vieira et al. (2013) teve como objetivo analisar os estilos parentais e suas relações com os níveis de motivação atletas de futebol das categorias infantil e juvenil. Para analisar os estilos parentais foi utilizado um instrumento que avaliava o suporte das figuras maternas e paternas a partir de três escalas: suporte emocional, rejeição e superproteção. Os resultados mostraram que as mães apresentam mais aspectos emocionais, tentativas de 
controle e favorecimento de assuntos para com seus filhos, havendo um estilo mais protetor sobre a criança. O papel da figura materna é relevante na manutenção da motivação intrínseca dos atletas de futebol. Quanto o papel do pai, as variáveis da motivação verificaram que a rejeição e a desmotivação são maiores em relação às mães, por isso, entende-se que o próprio comportamento dos pais em relação aos filhos homens, no que diz respeito ao rendimento esportivo, são claramente diferenciados.

A presença dos pais na arquibancada, atua de forma direta sobre o desenvolvimento psicológico do filho. Segundo Verardi e De Marco (2007) a maneira com a qual os pais interagem com seus filhos no âmbito familiar, será de certa forma também retratada no convívio em sociedade, influenciando assim a maneira que a criança se comporta durante o período das aulas e nos esportes. Este comportamento define muitas vezes a continuidade, o prazer e a perspectiva da criança em relação à modalidade esportiva vivenciada.

Um agente incentivador importante que contribuiu para a motivação das crianças é a participação dos pais nos jogos. Podemos verificar esse dado, analisando a tabela 5 :

Tabela 5: Acompanhamento dos jogos

\begin{tabular}{c|c} 
Acompanhamento dos jogos & $\%$ \\
\hline Frequentemente & 54,4 \\
Todos os jogos & 38,9 \\
Raramente & 6,7
\end{tabular}

É importante ressaltar que, além do incentivo à prática esportiva, o acompanhamento dos pais durante os jogos de seus filhos torna-se importante, pois a criança e o adolescente no transcorrer de um jogo estão diante da oportunidade de competir e, consequentemente, de demonstrar suas habilidades. (HARRIS, 1996, BAXTER-JONES; MAFFULLI, 2003). 
Para Torregrosa et al. (2008) ao receber o apoio e aprovação parental, as crianças sentem prazer e satisfação para a prática esportiva, e por isso se sentem encorajadas e motivadas a se comprometer ainda mais com o esporte que praticam, ao contrário disso, a criança pode sentir-se pressionada por esse fator externo e a prática esportiva acaba não sendo sadia.

A participação dos pais durante os jogos mostra a preocupação no aspecto do convívio familiar e da demonstração de carinho e apoio para a criança. Conforme Quarmby et al. (2011) as associações entre as atividades físicas e os comportamentos sedentários e a estrutura familiar das crianças estão relacionados. As crianças que moram em um ambiente familiar com pais separados possuem um risco maior de inatividade física em comparação a crianças que moram com ambos os pais biológicos. Alguns dos fatores podem favorecer esse efeito como a possibilidade das atividades de trabalho da mãe ou do pai não permitirem que algumas funções parentais essenciais sejam cumpridas, como supervisão das atividades diárias das crianças dentro ou fora de casa, incluindo acompanhamento ou prática de atividades esportivas. Então isso pode acarretar que a falta de interesse dos pais em atividades esportivas é transmitida às crianças. Este aspecto parece não se adequar ao presente caso, pois os resultados mostraram que $72 \%$ dos participantes da pesquisa são divorciados. A resposta para isto talvez esteja na atração que o futsal, como prática esportiva, exerce na comunidade caxiense.

De acordo com Vilani e Samulski, (2002 p. 23) "os pais influenciam direta e indiretamente a carreira esportiva de seus filhos. A motivação, o estresse, o comportamento emocional, dentre outros aspectos, podem estar relacionados ao envolvimento destes neste contexto." O trabalho com crianças no esporte não pode apenas reproduzir o ambiente esportivo profissional, deve aproximar o contexto das necessidades e direitos da criança, bem como da coerência e do compromisso para o seu desenvolvimento integral e harmônico, associado em todos os períodos de seu desenvolvimento esportivo. 
O envolvimento parental é de extrema importância, desde que promova autonomia para a criança, tenha coesão familiar e adaptações e não haja controle excessivo. Segundo Vieira et al. (2013), a participação dos pais junto aos filhos pode acarretar mudanças de comportamento em ambos os indivíduos, havendo maiores participações parentais nas atividades esportivas e um melhor desempenho por parte da criança. $\mathrm{O}$ incentivo e o acompanhamento dos pais para a prática esportiva de seus filhos constituem fatores de prazer e de satisfação para as crianças e adolescentes.

\section{Conclusões}

Podemos concluir que o esporte de uma maneira geral, e o futsal de maneira mais específica, é muito importante e valorizado no nordeste do estado do Rio Grande do Sul, pela sua tradição e seu aspecto cultural dentro do âmbito familiar. Concluímos que os pais terem praticado ou ainda praticarem algum esporte de forma recreativa/amadora/profissional acaba incentivando os seus filhos para que pratiquem alguma modalidade dentro do esporte.

O futsal, pela facilidade de se encontrar escolinhas esportivas na cidade, possui uma grande quantidade de praticantes. Isso se deve principalmente por este esporte ser muitas vezes a porta de entrada para o futebol que é tradicional e é bem mais valorizado culturalmente, socialmente e economicamente no nosso país.

Os pais por sua vez, por terem o esporte muito presente em sua vida, podem de uma maneira indireta colocar sob a criança os seus desejos e vontades que não puderam realizar, e por isso, acabam exigindo e pressionando a criança, aumentando assim seu nível de ansiedade. E por isso, podendo comprometer o seu desenvolvimento de forma geral e também específica dentro do esporte.

Porém, de uma maneira geral, os pais dos atletas dos clubes estudados, são participativos, proporcionam e principalmente incentivam os seus filhos dentro da modalidade de futsal. Esse incentivo acaba construindo um ambiente saudável 
para que a criança desenvolva suas potencialidades, sinta segurança e motivação para realizar tarefas e de contrapartida superar desafios existentes no esporte e também na sua vida.

Podemos afirmar que os pais possuem um papel crucial especialmente na infância, pois, há um enriquecimento da participação dos mesmos, possibilitando grandes experiências e principalmente a permanência no esporte.

\section{Referências}

ARINS, F. B.; SILVA, R. C. R. Intensidade de trabalho durante os treinamentos coletivos de futsal profissional: um estudo de caso. Revista Brasileira de Cineantropometria e Desempenho Humano, Florianópolis, v. 9, n. 3, p. 291296, 2007.

BAXTER-JONES, A. D.; MAFFULLI, N. Parental influence on sport participation in elite young athletes. Journal of Sports Medicine and Physical Fitness, v. 43, n. 2, 2003.

FIGUEIREDO, S. H. (2000). Variáveis que interferem no desempenho do atleta de alto rendimento. Em K. Rubio (Org.). Psicologia do esporte: interfaces, pesquisa e intenvenção (pp. 114-124). São Paulo: Casa do Psicólogo.

FONSECA, Gerard. M. M. A história do futebol de salão em Caxias do Sul: 1962 - 1996. (Dissertação de Mestrado) UFRGS, Porto Alegre, 2000.

FONSECA, Gerard. M. M.; SILVA, Mauro. A. Jogos de futsal: da aprendizagem ao treinamento. Caxias do Sul: EDUCS, 2002. 
FONSECA, Gerard. M. M, MANGINI, Rosana., ZECHIN, Franciele. Índice de permanência dos atletas nas categorias de base do futsal: uma análise longitudinal. Revista Motriz. V 19 N3. Resumos do XIV Congresso Internacional de Motricidade Humana. Pag. S288. jul/set, 2013.

GALLAHUE, David L. \& OZMUN, John, C. Compreendendo o Desenvolvimento Motor: bebês, crianças, adolescentes e adultos. São Paulo: Phorte Editora, 2003.

GIACOMONI, Cristian. FONSECA, Gerard. M.M. Principais indicadores de burnout em jovens atletas de futebol. (Trabalho de conclusão de curso) UCS, Caxias do Sul, 2012.

HARRIS, P. L. Criança e emoção: o desenvolvimento da compreensão psicológica. São Paulo: Martins Fontes, 1996.

LEONCINI, Marvio Pereira; SILVA, Márcia Terra da. Entendendo o futebol como um negócio: um estudo exploratório. Gestão e Produção. São Carlos, v. 12, n. 1, p.11-23, jan-abr, 2005.

MAGILL, Richard. A. Aprendizagem motora: conceitos e aplicações. São Paulo: Edgard Blücher, 1984.

MARQUES, G. M. Psicologia do Esporte: Aspectos que os atletas acreditam. Canoas: Editora Ulbra, 2003.

QUARMBY T, DAGKAS S, BRIDGE M. Associations between children"s physical activities, sedentary behaviours and family structure: a sequential mixed methods approach. Health Educ Res. 2011; 26: 63-76.

RAMOS, A. M.; NEVES, R. L. R. A iniciação esportiva e a especialização precoce à luz da teoria da complexidade. Revista Pensar à Prática, v. 11, n. 1, p. 1-8, 2008. 
VERARDI, C.E.L. ; DE MARCO, A. . Emoção e esporte: as relações entre pais e filhos numa experiência com o futebol. Revista da Educação Física, v. 18, 2007.

VERARDI, C. E. L.; DE MARCO, A. Iniciação esportiva: a influência de pais, professores e técnicos. Revista Eletrônica Da Escola de Educação e Desportos - UFRJ, Rio de Janeiro, v. 4, n. 2, p.103-119, 2008.

\section{VERARDI, C. E. L. Interferência dos pais e suas consequências na prática} do futebol na infância e adolescência: um estudo de caso. (Dissertação de Mestrado em Educação Física) Universidade Metodista de Piracicaba, Piracicaba, 2004.

VIEIRA, L. F. et. al. Estilos parentais e motivação em atletas jovens de futebol de campo. Revista Pensar à Prática, Goiânia, v. 16, n. 1, p. 13-19, 2013.

VILANI, L. H. P.; SAMULSKI, D. M. Família e esporte: uma revisão sobre a influência dos pais na carreira esportiva de crianças e adolescente. In: SILAMI GARCIA, E.; LEMOS, K. L. M. Temas atuais VII: Educação Física e Esportes. Belo Horizonte: Editora Health, 2002. p. 09-26.

SAMULSKI, D. Psicologia do Esporte. São Paulo: Manole Ltda, 2002.

SANTANA, W. C. de. Uma proposta pedagógica para o futsal na infância. Revista Unopar Científica, Londrina, v. 2, n. 1, p. 69-85, 1998.

SERPA, S. Treinar Jovens: complexidade, exigência e responsabilidade. Revista da Educação Física. Maringá, v. 14, n. 1, p. 75-82, 1. sem. 2003.

SIMÕES, A. C; BÖHME, M. T. S.; LUCATO, S. A. A participação dos pais na vida esportiva dos filhos. Revista Paulista de Educação Física, São Paulo, v. 13, n. 1, p. 34-45, 1999. 
TORREGROSA, M., SOUSA, C., VILADRICHI, C., VILLAMARÍN, F., e CRUZ, J. El clima motivacional y el estilo de comunicación del entrenador como predictores del compromiso en futbolistas jóvenes. Psicothema, 20(2), 254-259, 2008.

THOMAS, J. R; NELSON, J. K.; SILVERMAN. S. J. Métodos de pesquisa em atividade física. 5. ed. Porto Alegre: Artmed, 2007. 


\title{
Family and Sport: The Parental Influence on the Involvement of Children in the Competitive Indoor Soccer
}

\begin{abstract}
The aim of this study was to identify the parental factors determinants for the participation of the children in competitive indoor soccer. 149 adults participated, being 84 men and 65 women with children in the categories under 9, under 11 and under 13, from three indoor soccer clubs of Caxias do Sul - RS city. The instrument used for data collection was Questionnaire For Parents. The results showed that the sport is valued and practiced by parents. The study concludes that parental encouragement builds a healthy environment for children to develop their potential, safety and motivation to practice indoor soccer and that there is no significant difference in behavior between fathers and mothers.
\end{abstract}

Keywords: Sport. Indoor soccer. Motivation. Family.

\section{Familia y Deporte: La Influencia de los Padre en la Participación de los Hijos en el Fútbol Sala de Competición}

Resumen: El objetivo de estudio fue identificar los hechos determinantes para la participación de los hijos en el fútbol sala de competición. Han participado 149 adultos, siendo 84 padres y 65 madres con hijos en los niveles sub-9, sub-11 y sub-13 de tres clubes de fútbol sala de Caxias do Sul-RS. La recogida de los datos se hizo con el Cuestionário Para los Padres (QPP). Los resultados demuestran que el deporte tiene valor por los padres, además de practicarlo. La investigación concluye que la motivación de los padres contribuye para un ambiente sano para que los niños desarrollen sus capacidades, la autoconfianza y la motivación hacia la práctica del fútbol sala y que no hay diferencia entre el comportamiento de los padres y de las madres.

Palabras clave: Deporte. Fútbol Sala. Motivación. Familia. 